\title{
IDL Cholesterol and VLDL Cholesterol Subtype 3 Measurement
}

National Cancer Institute

\section{Source}

National Cancer Institute. IDL Cholesterol and VLDL Cholesterol Subtype 3 Measurement. NCI Thesaurus. Code C147371.

The determination of the amount of IDL cholesterol and VLDLD cholesterol subtype 3 present in a sample. 